\title{
A RARE CASE OF DEBILITATING HEADACHE AND ANAPLASTIC OLIGOASTROCYTOMA OF FRONTAL LOBE
}

Prathibha Shiveshi', Prajwal Karekatte Channappa², Pratheek Karekatte Channappa ${ }^{3}$

${ }^{1}$ Consultant Ophthalmologist, Department of Ophthalmology, Vasan Eye Care, Bangalore, Karnataka, India.

${ }^{2}$ Assistant Professor, Department of General Medicine, Rajarajeshwari Medical College, Bangalore, Karnataka, India.

${ }^{3}$ Assistant Professor, Department of General Surgery, Rajarajeshwari Medical College, Bangalore, Karnataka, India.

HOW TO CITE THIS ARTICLE: Shiveshi P, Channappa PK, Channappa PK. A rare case of debilitating headache and anaplastic oligoastrocytoma of frontal lobe. J. Evolution Med. Dent. Sci. 2019;8(01):91-93, DOI: 10.14260/jemds/2019/20

\section{PRESENTATION OF CASE}

A 25-year-old female patient from Mandya, Karnataka came to Ophthalmology OPD at Vasan Eye Care, Bangalore. Complaint of headache since one month. Headache initially was bi-frontal then gradually become holocranial. Headache was more at night causing patients to wake up from sleep. She was complaining of blurring of vision at peak of headache. Headache used to subside with oral analgesics. No history of vomiting or loss of consciousness or seizure with no other symptoms of raised intra cranial pressure were found.

On examination, patient was conscious and alert with normal mental function. Normal visual acuity of $6 / 6$ in both eye with normal colour vision test and visual field test were found. On fundus examination, bilateral grade 2 papilledema was seen. Ophthalmoscopic examination: Fundus showed swelling of disc with elevation and obscuration of $>1$ segment of the major blood vessels, peripapillary halo, splinter haemorrhages and exudates.

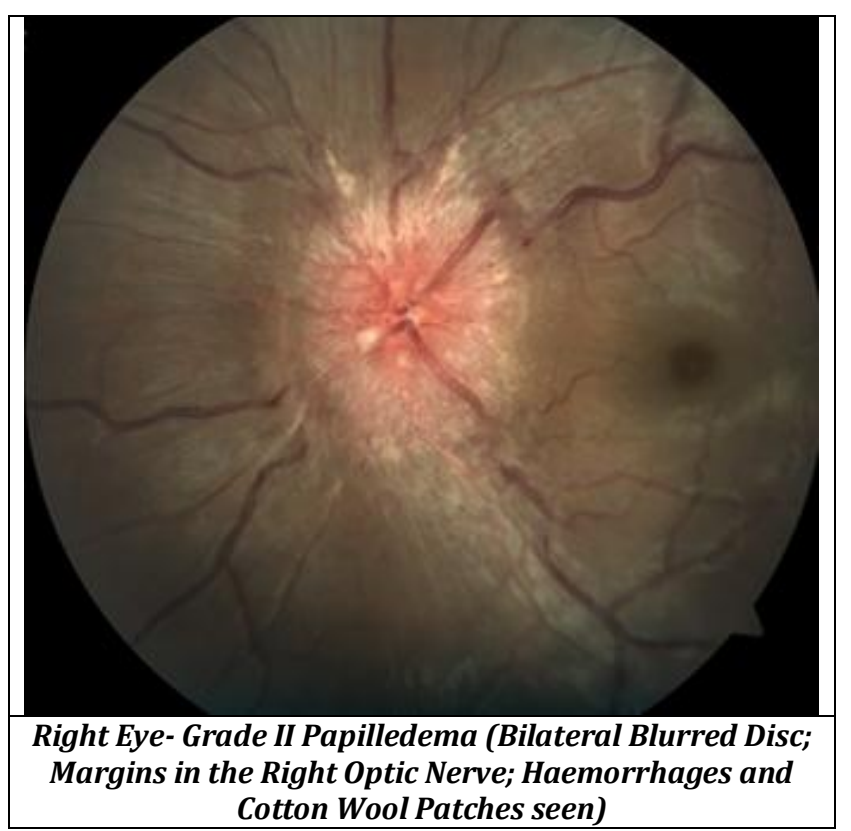

'Financial or Other Competing Interest': None. Submission 30-11-2018, Peer Review 23-12-2018,

Acceptance 31-12-2018, Published 07-01-2019.

Corresponding Author:

Prathibha Shiveshi,

\#32, Sai Krupa,

Mountain Street, Jayanagar $1^{\text {st }}$ Block, Bangalore-560011, Karnataka, India.

E-mail:dr.prathlaxmi@gmail.com

DOI: $10.14260 /$ jemds $/ 2019 / 20$

\section{(c) $(1) \odot$}

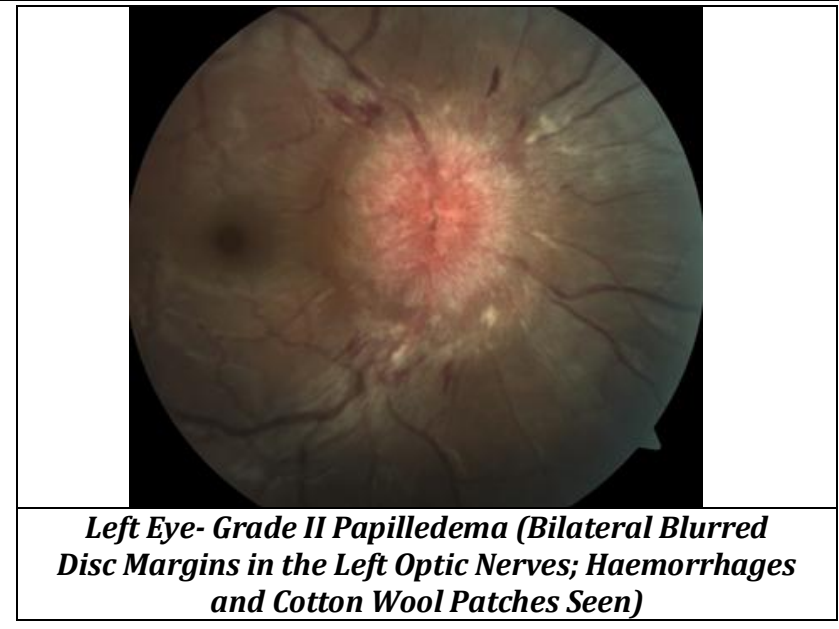

\section{CLINICAL DIAGNOSIS}

Bilateral Grade II Papilledema.

\section{DIFFERENTIAL DIAGNOSIS}

1. Intra Cranial Space Occupying Lesions.

2. Hypertensive Retinopathy.

3. Diabetic Papillopathy.

4. Graves Disease.

\section{PATHOLOGICAL DISCUSSION}

Histopathology report showed anaplastic oligoastrocytoma: The classical appearance of oligoastrocytoma is that of a round to oval, water-clear cytoplasm ringing about round to lobulated nuclei.

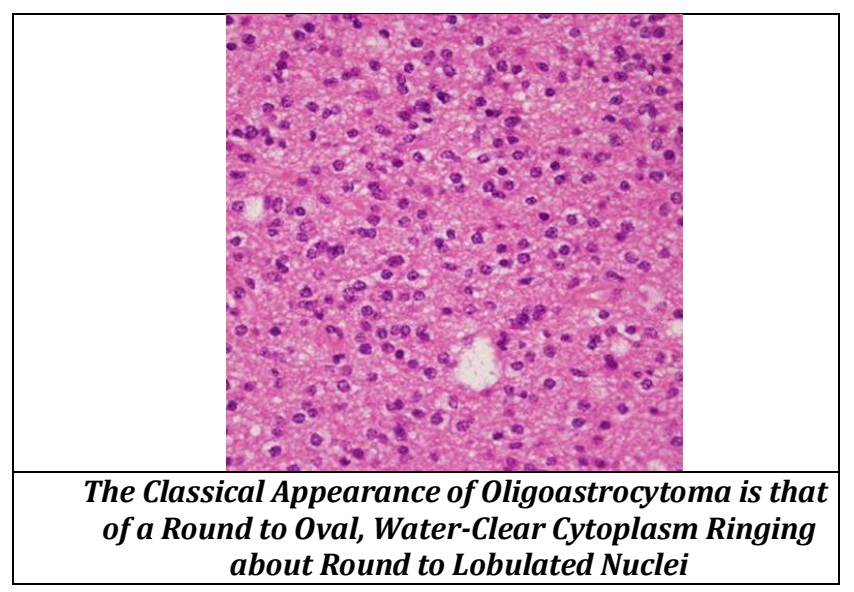

Later patient advised to undergo CT brain scan which showed right frontal iso to hypodense lesion with perilesional oedema with mass effect on subfalcine herniation and effacement of ipsilateral lateral ventricle i.e. frontal lobe tumour.

CT scan image: Oligoastrocytoma a) sagittal section b) Axial CT image shows a iso to hypoattenuating mass in the cortex and subcortical white matter of the right frontal lobe. 


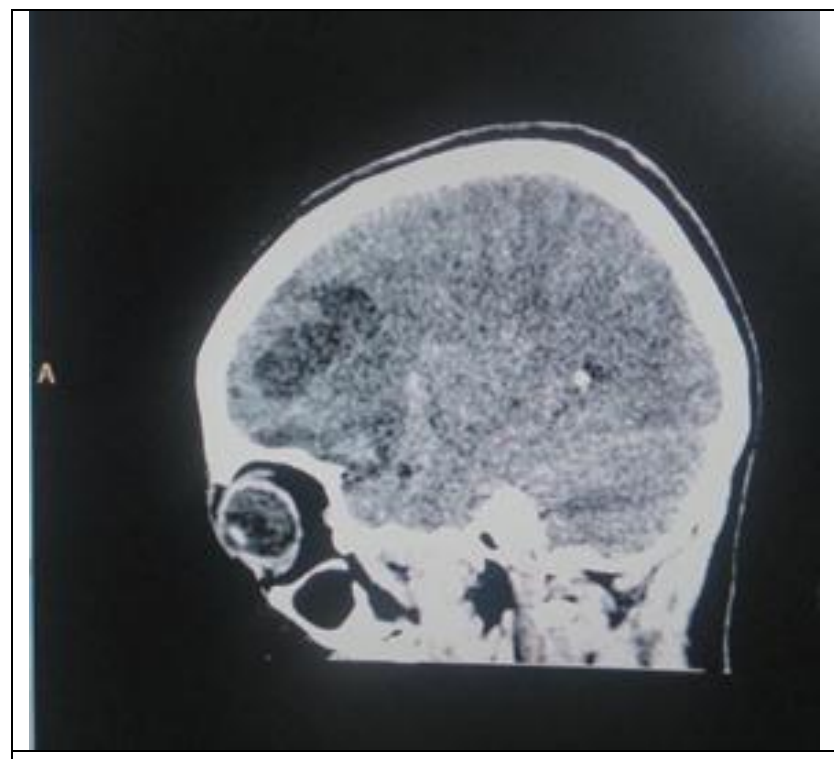

a) Sagittal Section of Brain

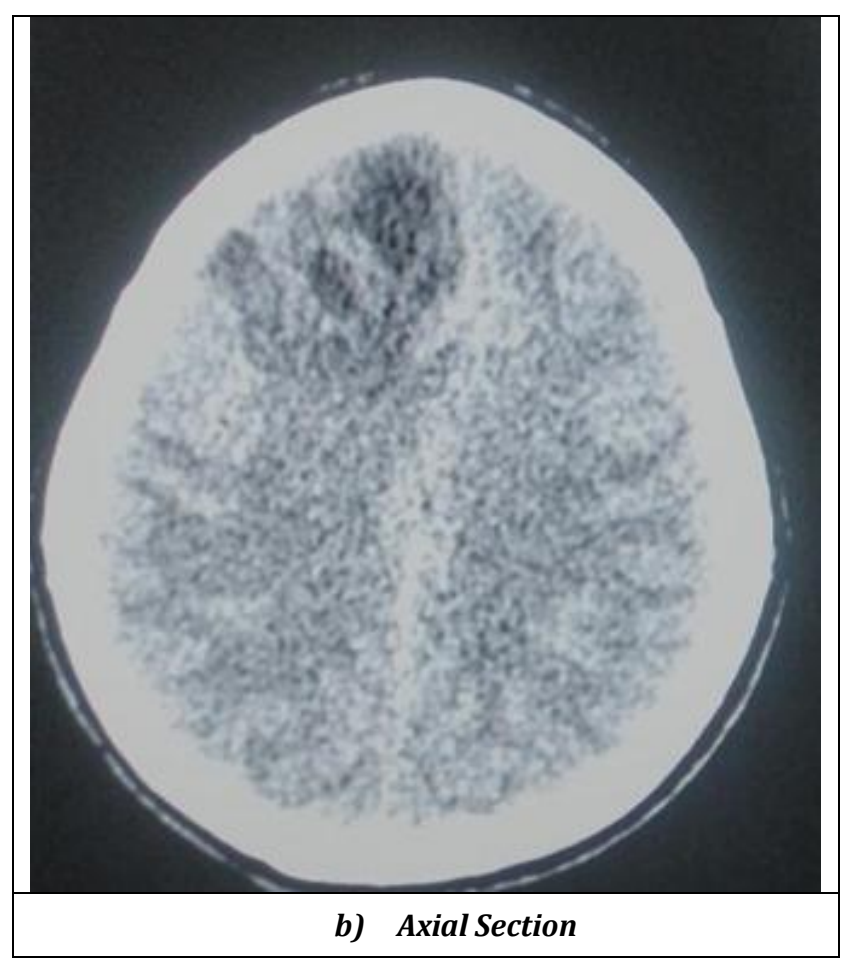

Patient was further asked for history of frontal area functions and there was no history of change in speech pattern, no history of altered behaviour with no history of memory loss and seizures. And patient was examined for primitive and grasp reflexes which found to be normal.

\section{DISCUSSION OF MANAGEMENT}

Patient underwent 3/4th of coronal flap craniotomy and decompression of lesion with excisional biopsy. Intra operative findings- Right frontal craniotomy with placement of medial burr hole just lateral to midline on the same side. Dura was torn during craniotomy on the medial aspect of frontal sinus which was not opened. Dura was tensed and bulging, brain was bulging and pulsatile. Superior and medial frontal gyri appear widened with normal appearing surface architecture. Craniotomy done in middle frontal gyrus and deepened. Lesion was visualised, greyish red soft to firm in consistency, moderately vascular. Lesion was decompressed in piece meal manner. Areas of necrosis cystic cavities were noted within the lesion containing brownish tinged fluid thrombosed veins noted at places. Frontal horn of ipsilateral lateral ventricle got inadvertently opened during decompression of the lesion. Right ACA identified and preserved. Cross total decompression of the lesion was done. Haemostasis was achieved. Duramater was repaired primarily. Brain was lax and pulsatile at the end of procedure. Bone was replaced with the drain placed epidurally. Excised brain matter were sent for histopathological examination.

This 25-year-old lady presented with complaints of headache since one month without any symptoms of raised intracranial pressure and sings of frontal lobe tumour. With the aforementioned clinical features of grade 2 papilledema of both eye and imaging studies, she was diagnosed to have right frontal high-grade glioma with mass effect. For which she underwent $3 / 4^{\text {th }}$ coronal flap craniotomy and decompression of lesion. And histopathology report showed anaplastic oligoastrocytoma. Followed by surgery the headache was subsided.

Papilledema is clinically defined as the optic disc swelling secondary to increased intracranial pressure. Papilledema is frequently bilateral and symmetric, but may be asymmetric or unilateral. The etiology for the high ICP or intracranial hypertension (IH) may be known (eg, brain tumor, meningitis, cerebral venous sinus [CVS] thrombosis) or may be unknown (ie, idiopathic). ${ }^{1}$

Anaplastic oligodendroglioma (AO) is a rare malignant tumour with features of oligodendroglial lineage and histological features corresponding to World Health Organization (WHO) grade III. $^{2}$ The reported annual incidence rates of $\mathrm{AO}$ ranges from 0.07 to 0.18 per 100,000 person-years and comprise only $0.5 \%$ to $1.2 \%$ of all primary brain tumours.3,4 Only about $30 \%$ of oligodendroglial tumours have anaplastic features. The peak incidence of $\mathrm{AO}$ is between 45 and 50 years of age. AO tends to preferentially occur in the frontal lobe, with the temporal lobe the next most common location. Seizures are the main presenting symptom, and speech and behaviour changes. . In such cases it is important to utilize modern neuro -radiological procedures like CT scan and MRI in order to detect the lesion to localize it. ${ }^{5}$

Oligoastrocytoma account for $5 \%$ to $20 \%$ of all diffuse gliomas, amounting to an annual incidence rate of approximately 0.4 per 100,000 person-years. With Peak age of 30 to 40 years, Male: Female ratio of $3: 2$. In this classification scheme, oligodendrogliomas are divided into two forms: the well-differentiated oligodendroglioma and the less common anaplastic oligodendroglioma. ${ }^{6-8}$ Common in frontal lobe and temporal lobe. Usually presents with seizures, headache and personality changes.

Headache in the emergency room has a wide differential diagnosis therefore systemic and organized approach is required to rule out any intracranial space occupying lesion. In contrast, several larger neurosurgical series found papilledema in up to $60 \%-80 \%$ of patients with cerebral tumours. 9,10 Even if patient does not complain of any symptoms and sign of intra cranial space occupying lesion. As our patient had complained of headache for which a routine examination of refraction and fundus examination was done 
and diagnosed having frontal lobe tumour. Hence complete ocular examination including fundus examination should be done to all headache patient to rule out life threatening diseases.

\section{FINAL DIAGNOSIS}

Anaplastic Astrocytoma

\section{REFERENCES}

[1] Lee AG, Brazis P. Clinical pathways in neuroophthalmology: an evidence-based approach. $2^{\text {nd }}$ edn. New York, NY: Thieme Publishers 2003.

[2] Reifenberger G, Kros J, Louis D, et al. Anaplastic oligodendroglioma. 3rd edn. Lyon: WHO Press 2007.

[3] Ohgaki H, Kleihues P. Population-based studies on incidence, survival rates and genetic alterations in astrocytic and oligodendroglial gliomas. J Neuropath Exp Neurol 2005;64(6):479-89.

[4] Dolecek TA, Propp JM, Stroup NE, et al. CBTRUS statistical report: primary brain and central nervous system tumors diagnosed in the United States in 20052009. Neuro Oncol 2012;14(Suppl 5):v1-v49.
[5] Rathod V, Bhole A, Chauhan M, et al. Study of clinicoradiological and clinico-pathological correlation of intracranial space occupying lesion at rural center. The Internet Journal of Neurosurgery 2009;7(1):1-6. http://ispub.com/ijns/7/1/6003.

[6] Reifenberger G, Kros JM, Burger PC, et al. Oligodendroglioma. In: Kleihues P, Cavenee WK, eds. Pathology and genetics of tumours of the nervous system. Lyon, France: IARC Press 2000: p. 56-61.

[7] Kros JM, Troost D, van Eden CG, et al. Oligodendroglioma: a comparison of two grading systems. Cancer 1988;61(11):2251-9.

[8] Daumas-Duport C, Tucker ML, Kolles H, et al. Oligodendrogliomas. Part II. A new grading system based on morphological and imaging criteria. J Neurooncol 1997;34(1):61-78.

[9] Petrohelos MA, Henderson JW. The ocular findings of intracranial tumor. A study of 358 cases. Trans Am Acad Ophthalmol Otolaryngol 1950;55:89-98.

[10] Allen ED, Byrd SE, Darling CF, et al. The clinical and radiological evaluation of primary brain tumors in children, Part I: clinical evaluation. J Natl Med Assoc 1993;85(6):445-51. 